\title{
Outsmarting the McKinsey-Brown argument? ${ }^{1}$
}

\section{Paul NoordhoF}

Externalists about mental content are supposed to face the following dilemma. Either they must give up the claim that we have privileged access to our own mental states or they must allow that we have privileged access to the world. The dilemma is posed in its most precise form through the McKinsey-Brown argument (McKinsey 1991; Brown 1995). Over the years since it was first published in 1991, our understanding of the precise character of the premisses which constitute the argument has been refined. It is based on three claims (where A partially serves to characterise the content of some belief state for which Externalism is true and E is some proposition about the external world).

(1) It is possible to know a priori that I think that A is F and that I am agnostic about the conditions of application of the concept of A.

(2) It is possible to know a priori that, if I think that A is $\mathrm{F}$ and that I am agnostic about the conditions of application of the concept of $\mathrm{A}$, then $\mathrm{E}$.

(3) It is not possible to know a priori that $\mathrm{E}$.

The charge is that (3) is inconsistent with (1) and (2). (1) is supposed to be a plausible thesis about our self-ascription of thoughts. (2) is supposed to be a commitment of Externalism. So either Externalists must give up (1) or concede that we do have a priori knowledge about the empirical world. Neither has been thought attractive.

The sense of a priori knowledge to which proponents of the McKinseyBrown argument appeal is that of knowledge which can be obtained independently of experience of the world (see Brown 1995: 149). I shall take thinking that $\mathrm{A}$ is $\mathrm{F}$ to be a case of occurrent thought. Some (e.g. McKinsey 1991: 9) have taken it to be the place-marker for a wider range of mental states but this undermines the force of the argument. Arguably, our self-ascription of some mental states depends upon our experience of things in the world (Dretske 1995: 41-44; Evans 1982: 225). Proponents of the argument don't have to resist this in order to present a challenge to Externalism. They can rely on the fact that it is most

1 Outsmart: to embrace the conclusion of one's opponent's reductio ad absurdum argument (Philosopher's Lexicon). 
implausible that the self-ascription of occurrent thought depends upon our experience of the world.

Jessica Brown is responsible for the most plausible formulation of E. It runs

(E) either I am in an environment which contains instances of A and the concept of A is a natural kind concept, or I am part of a community which has the concept of A, whether or not the concept of A is a natural kind concept. ${ }^{2}$ (Brown 1995: 154-55)

(E) is just the coupling together of the two forms of Externalism defended in the literature, namely that our possession of concepts depends upon the occurrence of entities in the natural environment or the existence of a linguistic community who possess the concept.

My aim is straightforward. I want to explain why the argument fails to establish a genuine dilemma. First, I will argue that Brown has failed to establish that we can know a priori that we are agnostic about the conditions of application of a concept, and hence failed to establish that premiss (1) is true. Anthony Brueckner (2002) also argued that Brown's support for premiss (1) is inadequate but his response strikes me as flawed for reasons which I shall outline. Second, I will argue that (2) is false, with particular reference to Brown's response to a challenge by Kevin Falvey (Falvey 2000; Brown 2001). Third, I shall explain why (3) is either false or no threat to the compatibility of Externalism with privileged access.

\section{Agnosticism}

In claiming that subjects can know a priori that they are agnostic about the application of a concept, Brown means that subjects can know a priori that they are unsure about whether a certain concept applies to a type of thing where there is a determinate fact about whether it does so apply (Brown 2001: 215). In such a case, she urges, Externalists must allow that we can know a priori either that there are instances of the relevant type of thing in the environment or that there is a linguistic community with that concept. These are the conditions they insist are necessary for there to be a determinate fact about a concept's application.

Brueckner denies that Externalists are committed to holding that we can know a priori that we are agnostic about a concept. He argues that knowledge about whether we are members of a linguistic community is an a posteriori matter. He continues

2 Brown actually talks of 'instances of A and A is a natural kind concept'. But this seems to be a slip. Water is not a natural kind concept but a liquid. So I've tacked in 'concept of A'. I've put the characterization and the argument into the first person for dramatic effect. 
Thus it is not ... clear to me that I know a priori that my word 'bureau' expresses a genuine concept having determinate application conditions. (Brueckner 2002: 91)

Let's agree with Brueckner that we cannot know a priori whether the word 'bureau' expresses a genuine concept. That does not touch on Brown's claim. Her claim does not concern whether we can know a priori that a certain word expresses a genuine concept. Instead, she asserts that part of what it is to grasp some concepts is to know that they have determinate application on some occasions even if we are uncertain what it is (Brown 2001:219-20). If this genuinely is part of what it is to grasp some concepts, then it is open to Brown to claim that, when subjects are having a thought properly specified in terms of that concept, they can move a priori to the fact that it has a determinate application on some occasion even though they are uncertain what it is. Then they can turn their attention to the truth or falsity of Externalism. If Externalism is true, it appears that determinate application in conditions of uncertainty implies the presence of, in the case of the concept of bureau, a linguistic community with that concept.

Even if a posteriori knowledge about one's membership of a linguistic community were required to know that the concept expressed by 'bureau' had determinate application under conditions of uncertainty, that would not mean that a master of the concept of bureau failed to know a priori that the concept had this feature. Experience required for possession of a concept does not make analytic truths about that concept a posteriori. Suppose, for the sake of argument, we cannot possess the concept of blue without having had experience of blue things. From that it would not follow that we could not arrive at the claim that blue is a colour a priori. So, by the same token, even if, in order to possess the concept of bureau, we would have to have appropriate interactions with a certain linguistic community, it would not follow that, as possessors of the concept, we could not know a priori that it had determinate application in conditions of uncertainty.

Contrary to Brueckner, then, I think it is worth turning to Brown's positive case for the claim that we can know a priori that we are agnostic about a certain concept (Brueckner 2002: 88). Brown's argument rests upon the thesis that reliable reasoning requires that there is, at worst, only limited partial understanding of the concepts at work (Brown 2001: 221-24). In Brown's hands, this means that while some analytic truths concerning a concept may not be knowable a priori, most will. Reliable reasoners need to be able to recognize the range of considerations which confirm and infirm their beliefs. That means that they must be able to grasp many of the analytic truths concerning their concepts in order to get the confirming and 
infirming relations right. For instance, one needs to know that the concept of contract does not apply only to written agreements in order to appreciate that a verbal agreement constituted a contract between the parties (Brown 2001: 221).

The problem for Brown is that, even if she is right that there are a priori considerations in favour of the claim that we must know many of the analytic truths concerning a concept, we are still some way off the claim that one of the analytic truths we can know a priori is that a concept has determinate application in conditions of uncertainty. Perhaps more damagingly, she is even some way off the claim that subjects must know most of the analytic truths a priori. Knowing them any which way would do for reliable reasoning. In particular, Tyler Burge's idea that by interaction and mutual persuasion thinkers seek to conform their incomplete understanding of a concept to the practice of others, the conventions settling the linguistic meaning of the term which expresses the concept, and certain archetypical applications, remains in play (Burge 1986: 702-3). Burge takes this to show that we don't know analytic truths a priori (Burge 1986: 700-707). So she has failed to establish, and does not look likely to be able to establish, that the Externalist must concede that the analytic truths concerning concepts must, in general, be known a priori. Although she commendably recognizes the programmatic nature of some of her reflections, she does not seem to appreciate that, for all she has shown, Burge's picture is the right one (Brown 2001: 222-23).

Of course, this does not establish that agnosticism about the application of a certain concept can't be known a priori. So it pays us to consider the other premiss of the argument.

\section{Manufactured concepts}

Falvey suggested that (2) is false because we might have manufactured our concept of A. He gives as his example gliver stipulated to apply to both gold and silver. Suppose I know a priori that I am having a thought that A is $\mathrm{F}$ and that $\mathrm{I}$ am agnostic about the conditions of application of the concept of A. Then it seems that I cannot conclude (E) but only

(E-) either I am in an environment which contains instances of $\mathrm{A}$ and concept of $\mathrm{A}$ is a natural kind concept, or I am part of a community which has the concept of $\mathrm{A}$, whether or not the concept of $\mathrm{A}$ is a natural kind concept, or $A$ is a manufactured concept.

(E-) involves no unhealthy a priori knowledge about the environment.

Brown's response is that cases like gliver would involve the wrong kind of agnosticism. She writes

if the natural environment allows the subject to have gold and silver, then no further environmental facts are required for him to have gliver 
despite his agnosticism ... the gliver subject can know a priori that his agnosticism about gliver stems wholly from his agnosticism about gold and silver. After all, the gliver subject is sure that gliver applies to something iff it is gold or silver, and can know that a priori. (Brown 2001: 218-19)

Brown's response is slightly surprising. In the past she has emphasized that Externalists rightly resist the idea that one can know a priori that a particular concept is atomic or of a natural kind (Boghossian 1997; Brown 1999: 54-57). Even if we agree that when subjects stipulate that gliver is gold or silver they know a priori the disjunctive root of their agnosticism, it doesn't follow that subjects will know this a priori some time after the stipulation. For instance, I might forget that I manufactured the concept gliver at time $t$ while still knowing a priori, at time $t+n$, that gliver has determinate application in conditions of uncertainty. It is hard to see how we could rule out a priori that this is our situation for most of the concepts we actually have since, by Brown's own lights, we can't know a priori which of them are atomic.

Suppose I remember that I did not manufacture the concept of bureau (say) and I know a priori, on the basis of my possession of the concept, that it has determinate application in conditions of uncertainty. Wouldn't I then have unhealthy a priori knowledge about the external world? No. First, the most obvious way in which I would remember that I did not manufacture the concept is by remembering that I obtained it from interaction with my socio-linguistic and/or natural environment. But that would make the knowledge a posteriori. The only alternative is that my memory that I did not manufacture the concept is worked out a priori from my having no memory that I did manufacture the concept. But now there is a problem. Although Externalists may allow that I can know a priori that I did not manufacture a concept in this case and that I can know a priori that a concept has determinate application in conditions of uncertainty, no sensible Externalist will concede that I can know a priori both of these at once. For instance, if I know a priori that I didn't manufacture a concept by these means, then this undermines the putative a priority of our knowledge that a concept has determinate application in conditions of uncertainty. I have a priori knowledge that the concept is a public one against which I must check my practice and about which I can develop the kind of exotic theories Burge describes, for example that our concept of bureau is the concept of a certain kind of religious artefact, or for that matter, fails to have the determinate application we suppose it to have in conditions of uncertainty (Burge 1986). Such theories cannot be dismissed a priori. In the previous section, I explained how Brown's argument failed to establish that we must know analytic truths about a concept a priori. The alternative Externalist 
picture in which analytic truths are not known a priori was still in play. But, in the circumstances envisaged now, we would not just have the alternative Externalist picture still in play but we would have a priori reason to suppose it applied.

If I can't know a priori both that the concept of A is not a manufactured concept and that it has determinate application in conditions of uncertainty, then premiss (2) is false. All I can know a priori is that if I am thinking that $\mathrm{A}$ is $\mathrm{F}$ and $\mathrm{I}$ am agnostic about the conditions of application of the concept of A, then E-. E-, unlike E, does not involve any unhealthy a priori knowledge about the external world.

\section{A priori knowledge of the external world}

Suppose that (1) is true and the resistance to (2) outlined in the previous section is set aside. Must Externalists then deny (3) and conclude that it is possible to know a priori that $(\mathrm{E})$ ? And if they must, is this a disaster? The answers depend upon the notion of a priori in play and the basis of the knowledge ascribed.

Let me focus on the a priori first. Here is one way of bringing out the issue. Everybody is supposed to accept that there are circumstances in which

(4) I know a priori that I think that $\mathrm{A}$ is $\mathrm{F}$ and that I am agnostic about the conditions of application of the concept of A.

Everybody is also supposed to concede that empirical research is still needed to decide whether $\mathrm{E}$ is the case. Let a subject's a priori grounds for a proposition be knowledge-sufficient a priori warrant if and only if, if the proposition is true, and the subject has these grounds for the proposition, then the subject knows the proposition in question. I leave it open whether knowledge-sufficient a priori warrant implies that the proposition is true. Proponents of the McKinsey-Brown argument now face a dilemma. If knowing a priori that $p$ requires knowledge-sufficient a priori warrant, then the need for empirical research to establish whether E suggests that

(2) It is possible to know a priori that, if I think that $A$ is $F$ and that I am agnostic about the conditions of application of the concept of $A$, then $E$.

is false. If, when the antecedent is true (and known to be true a priori), it is still a matter for empirical research whether the consequent is true, then the overall italicized conditional cannot be known a priori. Hence the McKinsey-Brown argument fails. On the other hand, if it is allowed that knowing a priori that $p$ just implies that one has some a priori grounds for $p$, then proponents of the McKinsey-Brown argument cannot take it as 
obvious that it is unacceptable to claim that (E) can be known a priori (see Sawyer 1998: 531-33, for an alternative challenge to this assumption). Making this claim is compatible with allowing that $(\mathrm{E})$ is a matter which still needs to be settled by empirical research. ${ }^{3}$

In response to the first horn of the dilemma, proponents of the McKinsey-Brown argument cannot insist that (2) is the Externalists' assumption rather than theirs. Externalists may base their conclusions on thought experiments but the issue raised is whether these thought experiments should be taken as entirely a priori or to include appeal to relatively obvious facts arrived at on the basis of experience about when it is appropriate to ascribe particular thoughts to thinkers. The conviction behind (3) shows us the extent to which the support for the conditional in (2) can be a priori, given various understandings of a priori. Externalists can concur with whatever verdicts are reached on the status of (2).

We have found one way in which the denial of (3) would be less counterintuitive than might be thought. Allowing that there is a priori knowledge that $\mathrm{E}$ is compatible with $\mathrm{E}$ requiring empirical support. Another way in which the denial of (3) is less counter-intuitive shows up when we focus on the basis of the knowledge we display in knowing a priori that E. Let us consider the case of my having the thought that water is wet and assume, with Brown, that the Externalist is committed to claiming that I know a priori that

either I am in an environment which contains water and the concept of water is a natural kind concept, or I am part of a community which has the concept of water, whether or not the concept of water is a natural kind concept.

In one sense, the a priori knowledge seems to be based upon the capacity to identify something highly specific about the nature of the external world. On the assumption that I am having a thought that water $\mathrm{H}_{2} \mathrm{O}$ is wet, then I know a priori that either water $\mathrm{H}_{2} \mathrm{O}$ is in the environment or that I am part of a language community with the concept of water $_{\mathrm{H}_{2} \mathrm{O}}$. The world must be in a quite specific way for the thought to be true. I put ' $\mathrm{H}_{2} \mathrm{O}$ ' as a sub-

3 The dilemma has implications for Martin Davies's treatment of the McKinsey-Brown argument. He puts forward the following Limitation Principle

Epistemic warrant cannot be transferred from $A$ to $B$, even given an a priori known entailment from $\mathrm{A}$ to $\mathrm{B}$, if the truth of $\mathrm{B}$ is a pre-condition of the knower even being able to believe the proposition A. (Davies 1998: 353)

If the first horn of the dilemma is taken up, the Limitation Principle is not needed to rule out unacceptable a priori knowledge of the external world. If the second horn is taken up, then the a priori knowledge is not necessarily unacceptable and the Limitation Principle rules out a perfectly legitimate path to knowledge. 
script to indicate the extension of the concept of water. It serves to indicate which concept I am expressing by 'water' to characterize appropriately the content of my mental states. It should not be assumed that attributing to someone the thought that water $\mathrm{H}_{2} \mathrm{O}$ is wet is attributing to them the thought that $\mathrm{H}_{2} \mathrm{O}$ is wet.

In another sense, though, my a priori knowledge is not based upon a capacity to identify something highly specific about the world at all. To see this, it is worth remembering to begin with that Externalists and Internalists are agreed that somebody who did have a thought that water $\mathrm{H}_{2} \mathrm{O}$ is wet would be unable to distinguish this thought from the thought that waterXYZ is wet. This can be brought out by imagining subjects slowly switching from earth to twin earth over a period of time and being asked whether their thoughts at time $t$ and time $t+n$ which they express by the phrase 'water is wet' are the same or different (see Falvey and Owens 1994: 110-11). Although the relevant thought experiment becomes more baroque it is easy to see that things are worse than this. Subjects not only cannot distinguish between water $\mathrm{H}_{2} \mathrm{O}$ and water XYZ thoughts, they also cannot distinguish their thought that water $\mathrm{H}_{2} \mathrm{O}$ is wet from the thought that water is wet, where 'water' picks out electrical stimulations brought about in a brain in a vat, or the machinations of a malicious demon, or a whole range of other phenomenally similar but microstructurally different substances in different possible worlds. By the same token, subjects' a priori knowledge that they are in a world either with water or with a speech community with the concept of water is compatible with their inability to distinguish between all the various scenarios just described.

The reason why people think that (3) must be true is that they note the way in which the ability upon which my a priori knowledge is based is highly specific while failing to note the way in which it is clearly highly unspecific. I'm not saying that the knowledge I should be ascribed is merely the knowledge that there is something called 'water' in my environment (whatever that environment is) or that a disjunction of circumstances holds (the ones outlined above). What I'm arguing is that the ability upon which the highly specific a priori knowledge is based is, in an important respect, no more specific than the capacity to identify the preconditions for having the thought that $p$ (where these preconditions are just thought of as whatever the preconditions are for having the thought that $p$ ).

So what the Externalist should say is that, although it looks as if the a priori knowledge they are committed to suppose that subjects have provides insight into the nature of the world in a quite specific respect, this a priori knowledge is not indicative of any capacity that would make such knowledge implausible to attribute. Any counter-intuitiveness is an illusion of the specificity of the content ascribed. 


\title{
4. The Externalist's response (in brief)
}

In brief, then, this is what the Externalist's response to the McKinseyBrown argument should be. First, nothing you have said persuades me that I must know a priori that I am agnostic about the concept of A but, second, even if I'm wrong, that's not a problem because you need me to know a priori that I haven't manufactured the concept of A at the same time and that is not at all plausible. However, third, suppose I give you this, then it still doesn't follow that you threaten my position. The conviction upon which you trade, namely that we can't find out things about the external world a priori, either establishes that the truth of Externalism is not a priori (in which case, fair enough) or is false when it is realized what 'finding out' comes to in this context. ${ }^{4}$

\author{
University of Nottingham \\ Nottingham NG7 2RD, UK \\ paul.noordhof@nottingham.ac.uk
}

\section{References}

Boghossian, P. 1997. What an externalist can know a priori. Proceedings of the Aristotelian Society 97: 161-75.

Brown, J. 1995. The incompatibility of anti-individualism and privileged access. Analysis 55: 149-56.

Brown, J. 1999. Boghossian on externalism and privileged access. Analysis 59: 52-59.

Brown, J. 2001. Anti-individualism and agnosticism. Analysis 61: 213-24.

Brueckner, A. 2002. Anti-individualism and analyticity. Analysis 62: 87-91.

Burge, T. 1986. Intellectual norms and foundations of mind. The Journal of Philosophy 83: 697-720.

Davies, M. 1998. Externalism, architecturalism, and epistemic warrant. In Knowing Our Own Minds, ed. C. Macdonald, B. Smith, and C. Wright, 1998, 321-61. Oxford: Oxford University Press.

Dretske, F. 1995. Naturalizing the Mind. Cambridge: Massachusetts, The MIT Press.

Evans, G. 1982. The Varieties of Reference. Oxford: Oxford University Press.

Falvey, K. 2000. The compatibility of anti-individualism and privileged access. Analysis 60: $137-42$.

Falvey, K. and J. Owens 1994. Externalism, self-knowledge and skepticism. The Philosophical Review 103: 107-37.

McKinsey, M. 1991. Anti-individualism and privileged access. Analysis. 51: 9-16.

Sawyer, S. 1998. Privileged access to the world. Australasian Journal of Philosophy 76: 523-33.

${ }^{4}$ I wish to thank an anonymous referee for Analysis and the Editor for making me express myself much more clearly, as well as acknowledge, more recently, the careful scrutiny and sensitivities of Lucy O'Brien. 